\title{
Electroanalytical Studies on the Interaction Of L-Serine-Based Schiff Base, HHDMP, with Copper in Sulphuric Acid
}

\author{
Mathew Kuruvilla ${ }^{1} \cdot$ Sam John $^{2} \cdot$ Abraham Joseph $^{1}$
}

Received: 15 April 2016/Revised: 15 June 2016/Accepted: 16 June 2016/Published online: 30 June 2016

(C) Springer International Publishing Switzerland 2016

\begin{abstract}
Amino acids and its Schiff bases have been widely recognized as green corrosion inhibitors primarily due to its non-toxic nature and biodegradable properties. Considering its unique nature and significant contribution in corrosion chemistry, studies were undertaken with an objective to find out the inhibitory effect of L-serine based Schiff base HHDMP on copper in 0.5, 1.0 and 1.5 M of sulphuric acid at 303, 308 and $313 \mathrm{~K}$. Various techniques such as weight loss method, electrochemical impedance spectroscopy, potentiodynamic polarization (Tafel), basic computational calculations and adsorption studies were employed in the present investigations. Results revealed that Schiff base HHDMP do offer attractive inhibition efficiency in all concentrations of sulphuric acid. The inhibition effect advanced with the increased concentration of the inhibitor. However, with the increased concentration, the inhibition efficiency showed decline trend. Such behaviour of the amino acid Schiff base HHDMP on copper in sulphuric acid may be due to surface adsorption of the inhibitor molecules on the metal, which contributes to decrease in the double-layer capacitance and increase in the polarization resistance.
\end{abstract}

Keywords Copper · HHDMP · EIS · Polarization · Weight loss

Abraham Joseph

drabrahamj@gmail.com

1 Department of Chemistry, University of Calicut, Calicut University PO, Malappuram, Kerala 673 635, India

2 SB College, Changanasserry, Kottayam, Kerala, India

\section{Introduction}

Copper and its alloys have been used from prehistoric times, and the importance of the metal today is greater than ever before. It is one of the non-ferrous materials widely used in various industries owing to its combination of excellent workability, high thermal and electrical conductivity, and attractive mechanical properties over a wide range of temperature and high resistance to electromigration [1]. Although copper is a noble metal, resistant against corrosion in nearly neutral and alkaline solution, it undergoes severe corrosion in highly acidic solution [2-4]. It is, therefore, the protection of copper is of great interest, especially in acidic media possessing chloride and sulphate ions [5-8]. The use of inhibitor is one of the most practical methods to protect metals from corrosion, especially in aggressive media. Various types of organic compounds are widely used as corrosion inhibitors to protect metals from quality deterioration due to corrosion. The organic compounds containing nitrogen, oxygen and sulphur are known to be effective as corrosion inhibitors for copper [9-13]. Since most of the inhibitors available are toxic in nature, these should be replaced with environment friendly inhibitors. Recently, the research efforts are prioritized towards the development of green corrosion inhibitors with good inhibition efficiency as well as least impact to environmental pollution. The isolation and identification of efficient and eco-friendly corrosion inhibitors became highly necessary as an alternative to toxic corrosion inhibitors. Reports are available on the effect of different amino acids on corrosion behaviour of different metals, but information on the effect of amino acid derived Schiff bases is lacking. There are, therefore, studies undertaken to find out the effect of L-serine amino acid Schiff base on copper under various concentrations of sulphuric acid medium at temperatures of 303,308 and $313 \mathrm{~K}$. 


\section{Materials and Methods}

\subsection{Inhibitor}

Schiff base, HHDMP (Z-3-hydroxy-2-((2-hydroxy-4a,8a,dihydronaphthalene-1-yl)methyleneamino)propanoic acid), (Fig. 1) was employed as inhibitor, and it was prepared as per the reported procedure [14]. HHDMP was prepared by dissolving 2-hydroxy-1-naphthaldehyde (10 m mol $1.72 \mathrm{~g}$ ) in $100 \mathrm{ml}$ methanol and then added to the amino acid Lserine $(10 \mathrm{~m} \mathrm{~mol})$ solution in methanol $(50 \mathrm{ml})$ for the preparation of HHDMP. The mixture was refluxed for $3 \mathrm{~h}$, and the solvent was removed on a rotary evaporator and the residue crystallized at room temperature. After a day, crystals were obtained and recrystallized from methanol/nheptane and characterized by physico-chemical methods. HHDMP: ${ }^{1} \mathrm{H}$ NMR (DMSO- $\left.\mathrm{d}_{6} ; \delta, \mathrm{ppm}\right): 9.06(\mathrm{~s}, \mathrm{HC}=\mathrm{N})$, 4(q, C-H), 4(m, $\left.\mathrm{CH}_{2}\right), 10.92(\mathrm{~s}, \mathrm{COOH}), 6.90-8.05$ (m, ArC$\mathrm{H})$ Infrared $\left(\mathrm{KBr}, \mathrm{cm}^{-1}\right): v(\mathrm{C}=\mathrm{N}), 1630 ; \mathrm{v}(\mathrm{COOH})$, 16384; $v(\mathrm{C}=\mathrm{O}), 16334 ; \mathrm{v}(\mathrm{O}-\mathrm{H}), 3306 \mathrm{~s}$.

\subsection{Medium}

The medium was prepared from reagent grade sulphuric acid (E. Merck) and double-distilled water. All tests were performed in aerated medium at 303, 308 and $313 \mathrm{~K}$ under atmospheric pressure.

\subsection{Materials}

The copper specimens of dimension $8 \times 1.9 \mathrm{~cm}^{2}$ were used in weight loss measurements ( $0-4$ grit of 1200 mesh). Coupons of same size were used for electrochemical studies, but only $1 \mathrm{~cm}^{2}$ area is exposed during each test. Before recording the measurements, the samples were polished using different grades of emery papers followed by washing with water and acetone as recommended by ASTM.

\subsection{Weight Loss Measurements}

The weight loss experiments were carried out according to the method described previously [15]. For weight loss studies, specimens of required dimension were cut and

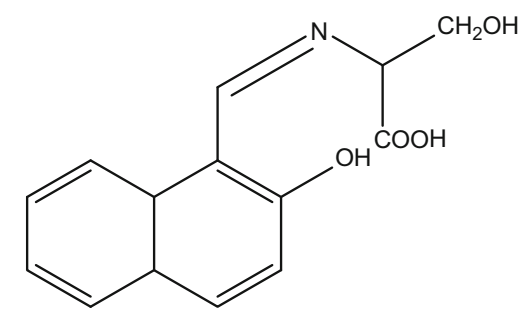

Fig. 1 Structure of HHDMP
Table 1 Inhibition efficiency (\%) of HHDMP for copper at different time intervals

\begin{tabular}{|c|c|c|c|c|}
\hline \multirow[t]{2}{*}{ HHDMP $\left(\mathrm{mgL}^{-1}\right)$} & \multicolumn{4}{|c|}{$\%$ Inhibition efficiency with time in hours } \\
\hline & 24 & 48 & 72 & 96 \\
\hline Blank & - & - & 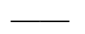 & - \\
\hline 50 & 68.21 & 66.36 & 62.58 & 59.63 \\
\hline 100 & 72.36 & 69.36 & 67.71 & 64.78 \\
\hline 150 & 74.89 & 71.61 & 70.86 & 68.89 \\
\hline
\end{tabular}

cleaned in acid solutions and later polished with finer grades of emery paper to mirror bright finish. Beaker $(250 \mathrm{ml})$ containing the solution was used for experimentation. After the stipulated exposure time, the specimens were removed from the test solution for washing initially with running tap water to remove the loosely adhering corroded particle and finally cleaned with a mixture of $20 \% \mathrm{NaOH}$ and $200 \mathrm{~g} / \mathrm{L}$ Zinc dust followed by acetone (ASTM). Subsequently, the loss in weight was determined using analytical balance. The inhibition efficiency \% IE was calculated using the equation

$\% \mathrm{IE}=\frac{W_{0}-W}{W_{0}} \times 100$,

where $\mathrm{W}_{0}$ and $\mathrm{W}$ represent weight losses in the uninhibited and inhibited solutions, respectively.

\subsection{Electrochemical Measurements}

Electrochemical tests were carried out in a conventional three-electrode configuration with platinum sheet $\left(1 \mathrm{~cm}^{2}\right.$ surface area) as auxiliary electrode and saturated calomel electrode (SCE) as the reference. The working electrode was first immersed in the test solution for an hour to establish a steady-state OCP [87-88]. The electrochemical measurements were carried out with a Gill AC computercontrolled electrochemical workstation (ACM, U.K model no: 1475). The potentiodynamic polarization curves were obtained in the potential range from -250 to $+250 \mathrm{mV}$ with a sweep rate of $1 \mathrm{mV} / \mathrm{s}$, and electrochemical impedance spectroscopy (EIS) measurements were carried out with amplitude of $5 \mathrm{mV}$ ac sine wave with a frequency range of $0.1-10000 \mathrm{~Hz}$.

\subsection{Computational Studies}

Various quantum chemical parameters of the inhibitor HHDMP (Z-3-hydroxy-2-((2-hydroxy-4a,8a,-dihydronaphthalene-1-yl)methyleneamino)propanoic acid) were calculated using B3LYP, which is a version of the DFT method that uses Becke's three-parameter functional (B3) and includes a mixture of HF with DFT exchange terms 
Table 2 Data on electrochemical parameters of copper obtained from polarization curves in $1 \mathrm{MH}_{2} \mathrm{SO}_{4}$

\begin{tabular}{|c|c|c|c|c|c|c|c|}
\hline Temp (K) & HHDMP (ppm) & $\mathrm{E}_{\text {corr }}(\mathrm{mV})$ & $\beta_{\mathrm{a}}(\mathrm{mV}$ dec- 1$)$ & $\beta_{\mathrm{c}}(\mathrm{mV}$ dec-1) & $\mathrm{I}_{\text {corr }}\left(\mathrm{mA} \mathrm{cm}^{-2}\right)$ & CR (mils/yr) & (\% IE) \\
\hline \multirow[t]{4}{*}{303} & Blank & -39.52 & 61.15 & -184.44 & 0.0110 & 10.30 & - \\
\hline & 50 & -79.20 & 57.76 & -110.72 & 0.0032 & 3.010 & 71.42 \\
\hline & 100 & -72.60 & 54.32 & -62.13 & 0.0021 & 2.560 & 75.89 \\
\hline & 150 & -110.32 & 37.12 & -56.45 & 0.0020 & 2.100 & 80.35 \\
\hline \multirow[t]{4}{*}{308} & Blank & -52.20 & 43.77 & -275.60 & 0.0090 & 11.26 & - \\
\hline & 50 & -80.65 & 56.29 & -90.64 & 0.0032 & 3.25 & 68.68 \\
\hline & 100 & -110.25 & 45.97 & -68.57 & 0.0024 & 2.60 & 71.74 \\
\hline & 150 & -84.87 & 64.45 & -99.30 & 0.0025 & 2.23 & 74.74 \\
\hline \multirow[t]{4}{*}{313} & Blank & -53.21 & 47.32 & -396.42 & 0.0126 & 11.57 & 一 \\
\hline & 50 & -78.63 & 58.67 & -144.30 & 0.0040 & 3.73 & 66.66 \\
\hline & 100 & -39.56 & 36.93 & -50.42 & 0.0038 & 3.49 & 69.84 \\
\hline & 150 & -80.47 & 58.20 & -92.04 & 0.0034 & 3.11 & 73.01 \\
\hline
\end{tabular}

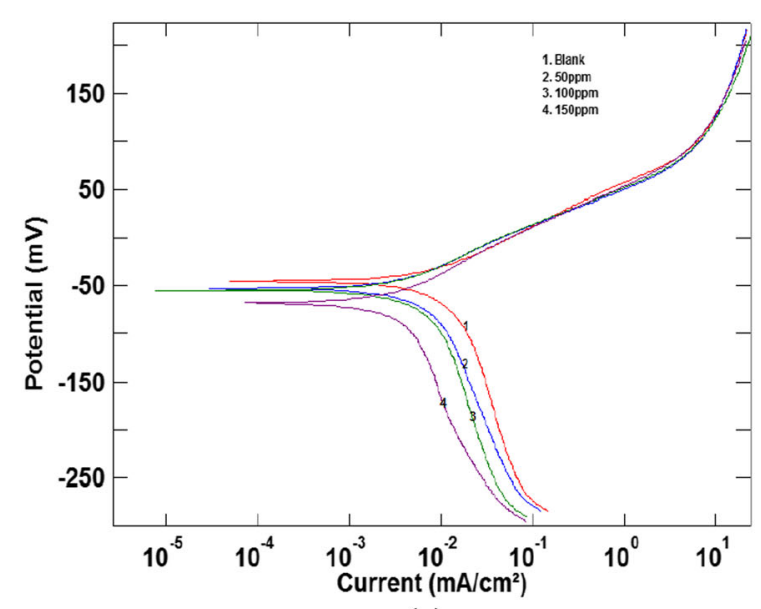

(a)

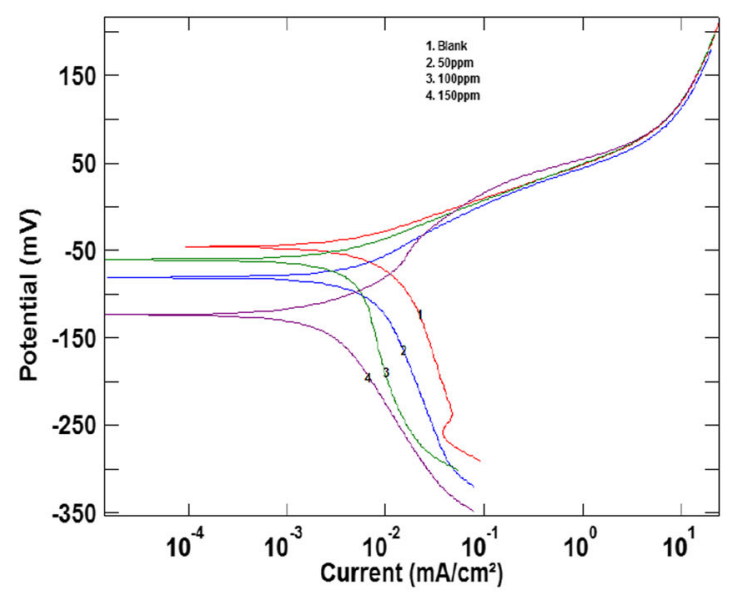

(b)

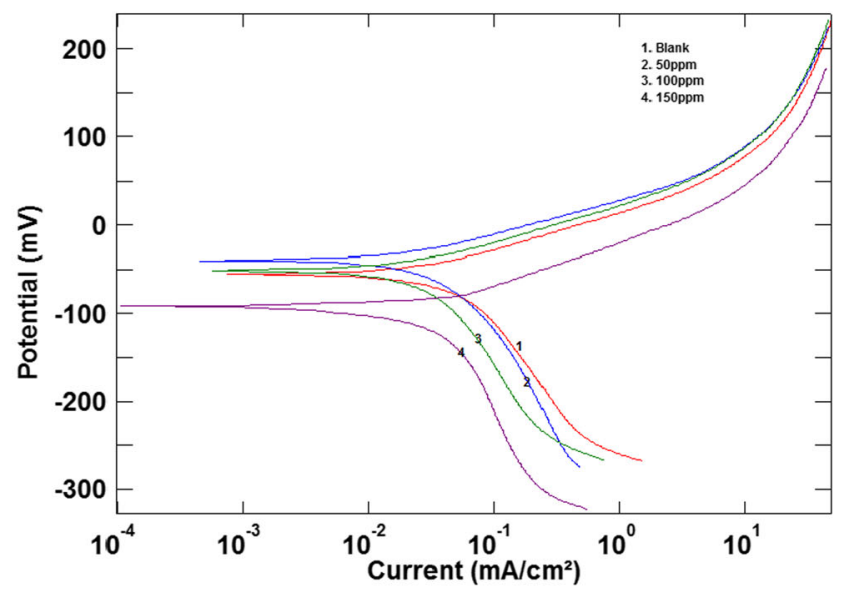

(c)

Fig. 2 Polarization curves for copper in $1 \mathrm{M}$ sulphuric acid at 303, 308 and $313 \mathrm{~K}$, respectively

associated with the gradient corrected correlation functional of Lee, Yang and Parr [16]. It was recognized specifically for systems containing transition metal atoms
$[17,18]$, and hence, B3LYP was used in the present study to carry out quantum calculations. Subsequently, full geometry optimization of the inhibitor was carried out at 
Fig. 3 Plot of $I_{\text {corr }}$ against inhibitor concentration in $1 \mathrm{M}$ sulphuric acid at a $303 \mathrm{~K}$, b $308 \mathrm{~K}$ and c $313 \mathrm{~K}$

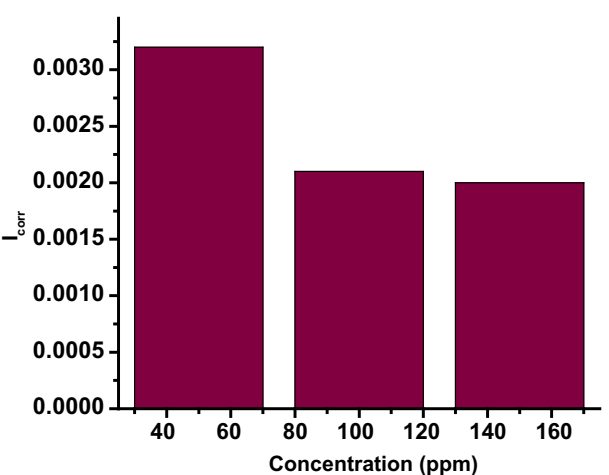

(a)

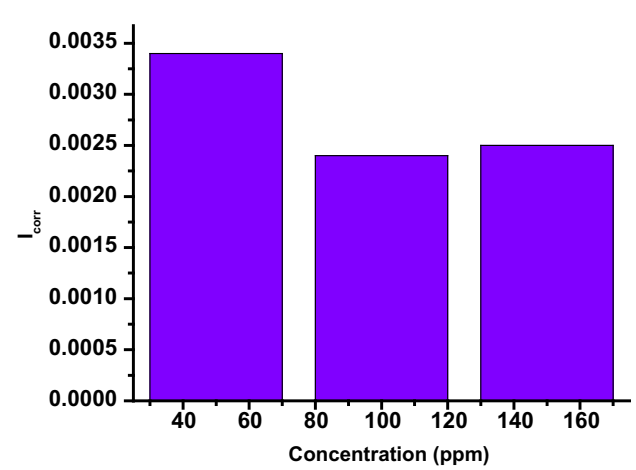

(b)

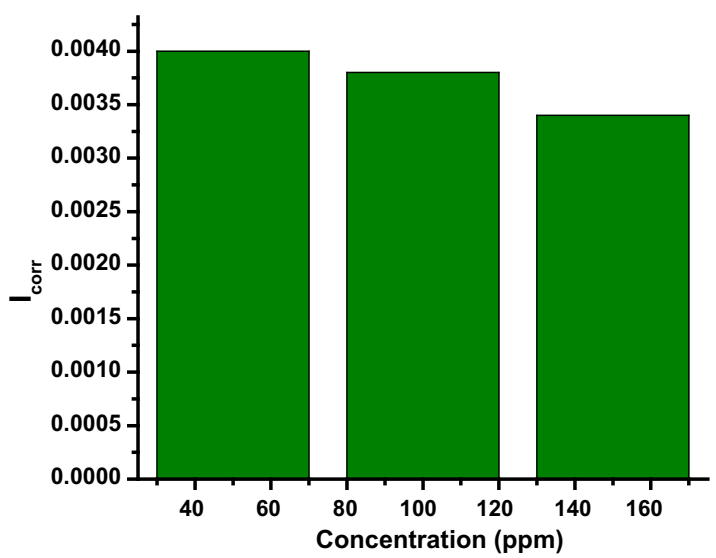

(c)

Table 3 AC impedance data on copper with HHDMP in $1 \mathrm{M}$ $\mathrm{H}_{2} \mathrm{SO}_{4}$ at 303,308 and $313 \mathrm{~K}$

\begin{tabular}{lllclcc}
\hline Temp $(\mathrm{K})$ & HHDMP $(\mathrm{ppm})$ & $\mathrm{R}_{\mathrm{ct}}\left(\Omega \mathrm{cm}^{2}\right)$ & $\mathrm{C}_{\mathrm{dl}}\left(\mu \mathrm{F} \mathrm{cm}{ }^{-2}\right)$ & $\mathrm{I}_{\text {corr }}\left(\mathrm{mA} \mathrm{cm}^{-2}\right)$ & C.R (mils/yr) & $(\% \mathrm{IE})$ \\
\hline 303 & Blank & 493 & 409.10 & 0.052 & 48.38 & - \\
& 50 & 1533 & 315.30 & 0.017 & 15.58 & 68.84 \\
& 100 & 2588 & 261.60 & 0.010 & 9.23 & 80.95 \\
308 & 150 & 3273 & 234.00 & 0.008 & 7.52 & 85.98 \\
& Blank & 442 & 1430.00 & 0.058 & 54.02 & - \\
& 50 & 1311 & 173.00 & 0.019 & 18.15 & 67.28 \\
313 & 100 & 1772 & 107.80 & 0.014 & 13.48 & 75.05 \\
& 150 & 2715 & 76.00 & 0.009 & 8.79 & 83.72 \\
& Blank & 438 & 1105.00 & 0.060 & 54.96 & - \\
& 50 & 1298 & 318.20 & 0.020 & 19.36 & 66.00 \\
& 100 & 1715 & 54.22 & 0.015 & 13.93 & 74.40 \\
& 150 & 2512 & 29.13 & 0.010 & 9.51 & 82.50 \\
\hline
\end{tabular}

the B3LYP/6-311 + G (d, P) level using the Gaussian 09W program package.

\subsection{Scanning Electron Microscopy (SEM)}

The surface morphology of copper in the absence and presence of the inhibitor HHDMP was studied using a Digital Microscope Imaging Scanning electron microscope model SU6600 (Serial No: HI-2102-0003) with an accelerating voltage $20.0 \mathrm{kv}$. Samples were attached on the top of an aluminium stopper by means of carbon conductive adhesive tape. All micrographs of the specimen were taken at the magnification of $\times 500$.

\subsection{Atomic Force Microscope (AFM)}

The copper strips having a size of $8 \times 1.9 \mathrm{~cm}^{2}$ were immersed in $1.0 \mathrm{M} \mathrm{H}_{2} \mathrm{SO}_{4}$ with and without the inhibitor 


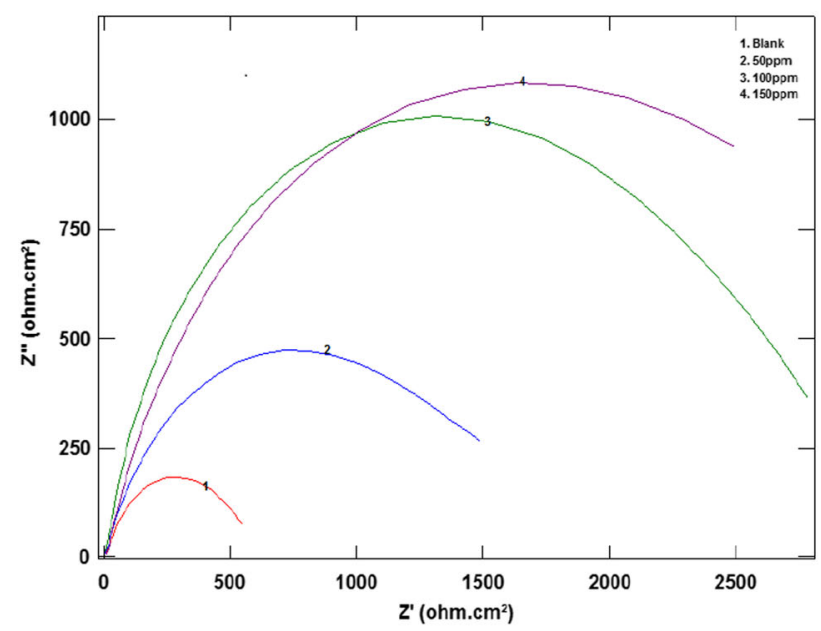

(a)

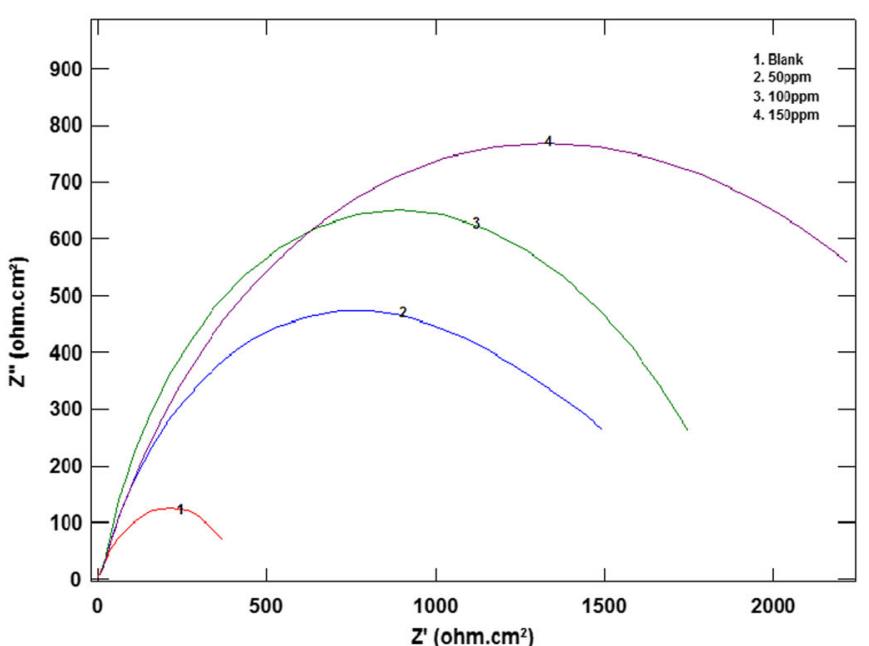

(b)

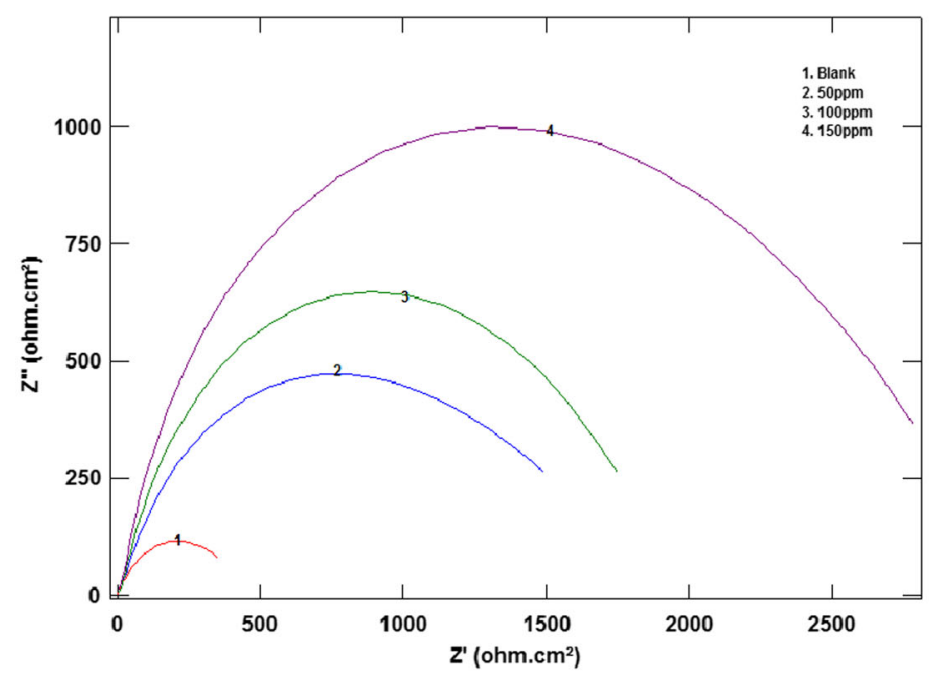

(c)

Fig. 4 Nyquist plots of copper in $1 \mathrm{M}$ sulphuric acid solution at a $303 \mathrm{~K}$, b $308 \mathrm{~K}$ and c $313 \mathrm{~K}$

$(150 \mathrm{ppm})$ at $303 \mathrm{~K}$ for $120 \mathrm{~h}$. The specimens were cleaned after the treatment period with distilled water, dried and then used for atomic force microscopic studies.

\section{Results and Discussion}

\subsection{Weight Loss Studies}

The weight loss recorded on the sample specimen reflects on the inhibition efficiency. The weight loss under different intervals of time $(24,48,72$ and $96 \mathrm{~h})$ in $1 \mathrm{M}$ sulphuric acid at different concentrations of inhibitor HHDMP was studied, and the results are summarized in Table 1. Results revealed that the inhibition efficiency is high at $24 \mathrm{~h}$ interval irrespective of the concentrations of the inhibitors and subsequently the efficiency declined. The inhibition efficiency increased with the increased concentrations of the inhibitor, however with the advancement of time interval inhibition efficiency decreased irrespective of the inhibitor concentrations. Similar observations were also reported in copper with Cysteine [19].

\subsection{Potentiodynamic Polarization Studies}

Potentiodynamic polarization behaviour of copper in $1 \mathrm{M}$ sulphuric acid in the absence and presence of inhibitor HHDMP at 303, 308 and $313 \mathrm{~K}$ are presented in Table 2. Results indicated that the electrochemical parameters vary with the inhibitor concentration and temperature. Tafel polarization curves for copper in $1 \mathrm{M}$ sulphuric acid in the absence and presence of different concentrations of HHDMP at 303, 308 and $313 \mathrm{~K}$ are presented in Fig. 2. The polarization results indicated that increase in the 
Fig. 5 Plot of efficiency against concentration of the inhibitor in $1 \mathrm{M} \mathrm{H}_{2} \mathrm{SO}_{4}$ at a $303 \mathrm{~K}$, b $308 \mathrm{~K}$ and $\mathbf{c} 313 \mathrm{~K}$

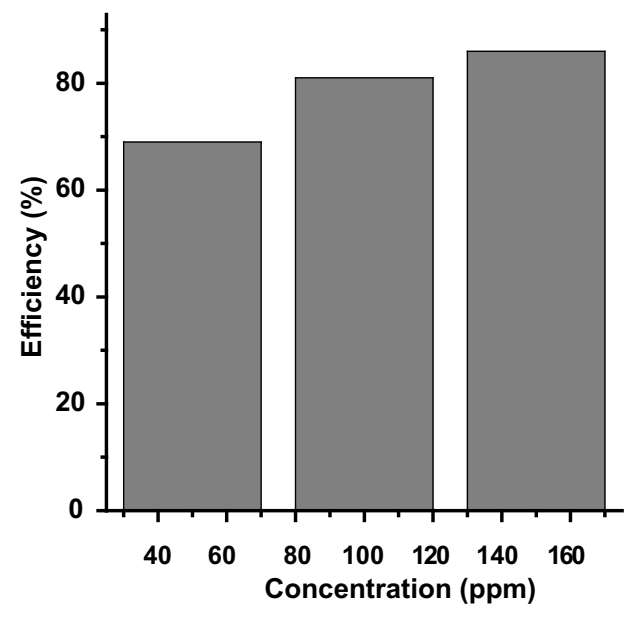

(a)

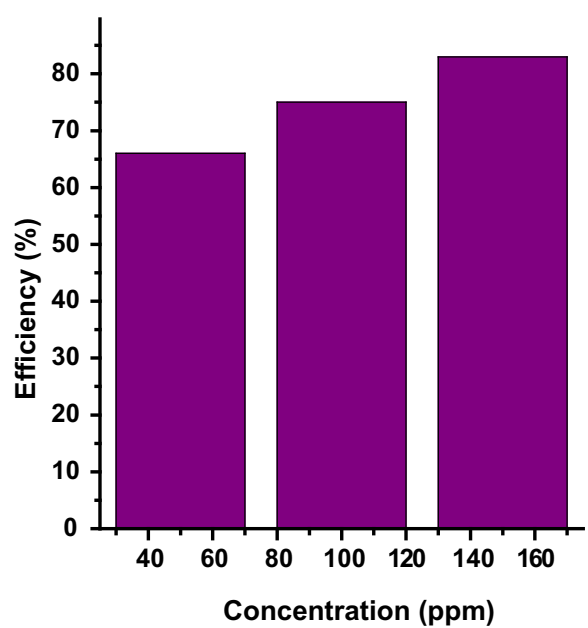

(b)

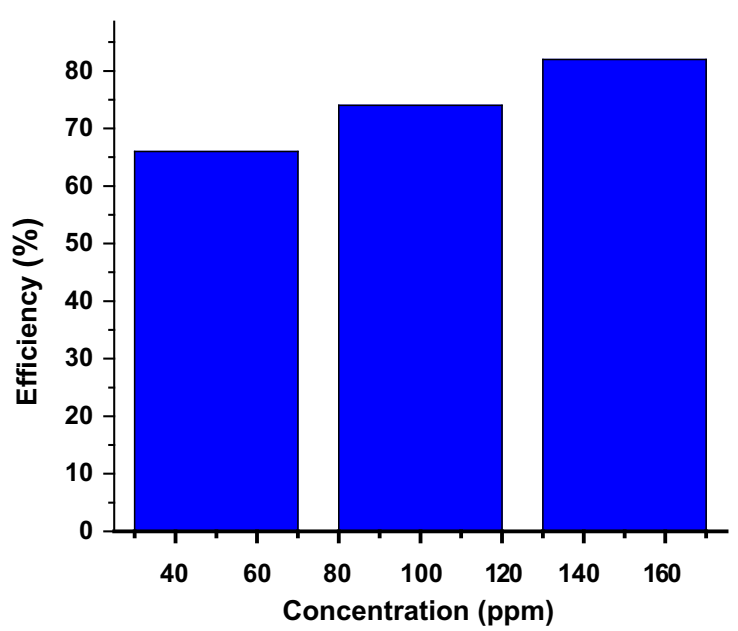

(c)

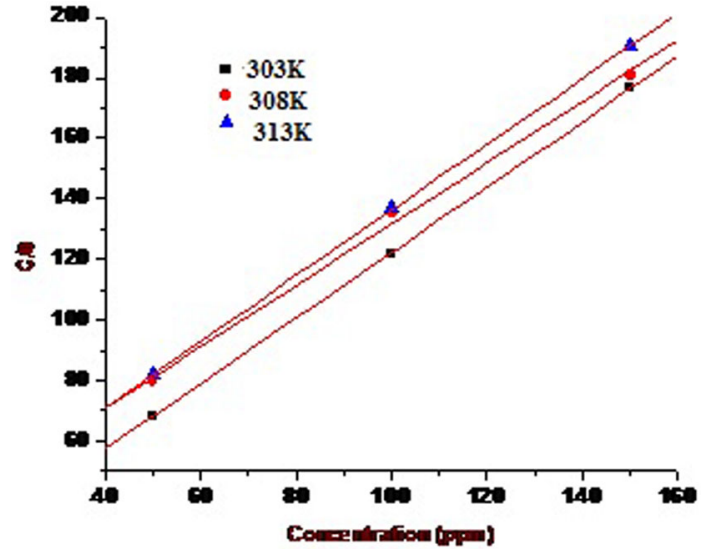

Fig. 6 Langmuir adsorption isotherm

inhibitor concentration changes both the cathodic and anodic current, and there is no definite trend in the shift of $\mathrm{E}_{\text {corr }}$ values. The displacement in $\mathrm{E}_{\text {corr }}$ value was less than
$85 \mathrm{mV}$ between blank acid solution and acid solution with the inhibitor, which confirms the mixed type behaviour of the inhibitor. Therefore, it is also clear that the values of electrochemical parameters like $I_{\text {corr }}$ and corrosion rate decreased with the increase in concentration of the inhibitor. The decreasing trend of $I_{\text {corr }}$ with the increase in inhibitor concentration in all the acid concentration is shown in Fig. 3. The corrosion inhibition efficiency was calculated using the equation

$\mathrm{IE} \%=\frac{\mathrm{I}_{\text {Corr }}-\mathrm{I}_{\text {Corr }}}{\mathrm{I}_{\text {Corr }^{*}}} \times 100$,

where $\mathrm{I}_{\mathrm{Corr}^{*}}$ and $\mathbf{I}_{\text {corr }}$ represent uninhibited and inhibited corrosion current densities.

The mechanism of corrosion inhibition involves the blocking of reaction sites by the inhibitor due to the adsorption of inhibitor molecule on the metal surfaces, and the surface adsorption increases by increase in the concentration of inhibitor [20]. The formation of a coating on 
Table 4 Adsorption parameters of inhibitor (HHDMP) for corrosion of $1 \mathrm{M} \mathrm{H}_{2} \mathrm{SO}_{4}$ at 303 , 308 and $313 \mathrm{~K}$

\begin{tabular}{|c|c|c|c|c|c|c|}
\hline \multirow[t]{2}{*}{ Temperature $(\mathrm{K})$} & \multicolumn{6}{|c|}{$\Delta \mathrm{G}_{\mathrm{ads}}^{\mathrm{o}}\left(\mathrm{kJ} \mathrm{mol}^{-1}\right) \& \mathrm{~K}_{\mathrm{ads}} \times 10^{4}\left(\mathrm{~mol}^{-1}\right) \operatorname{HHDMP}(\mathrm{ppm})$} \\
\hline & 50 & & 100 & & 150 & \\
\hline 303 & -16.18 & 11.00 & -16.19 & 11.12 & -16.08 & 10.68 \\
\hline 308 & -16.06 & 10.59 & -15.30 & 7.83 & -15.50 & 8.49 \\
\hline 313 & -15.95 & 10.13 & -15.17 & 7.42 & -15.33 & 7.91 \\
\hline
\end{tabular}

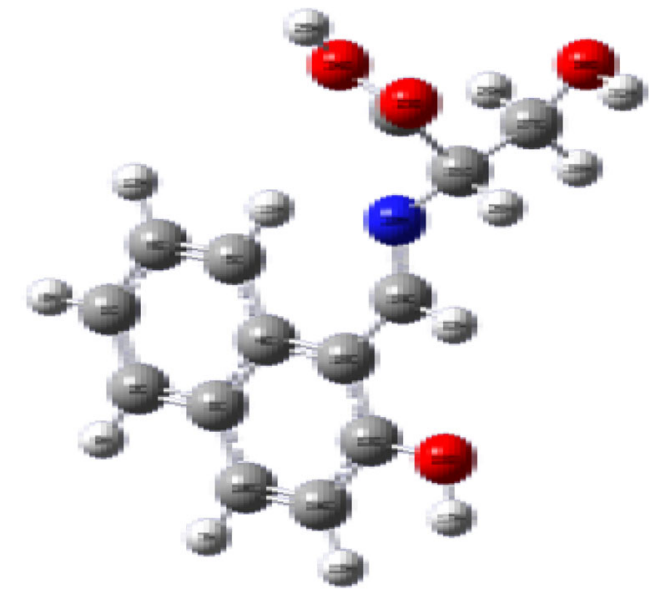

Fig. 7 Optimized geometry of HHDMP

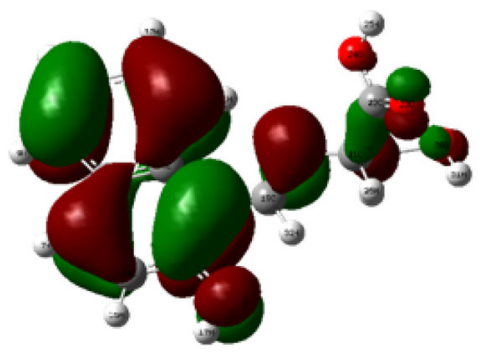

(a) HOMO

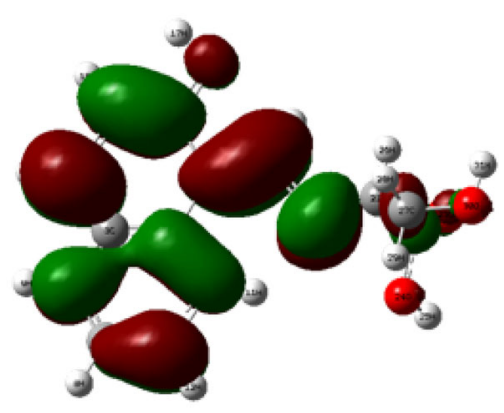

(b) LUMO

Fig. 8 a HOMO b LUMO of HHDMP

the surface of the metal as a result of adsorption of the inhibitor molecule gives a considerable protection against corrosion.

\subsection{Electrochemical Impedance Spectroscopy (EIS)}

Electrochemical impedance spectroscopy (EIS) is an efficient technique to study organic coatings on the metal as this technique does not disturb the double layer at the metal/solution interface and thus provides highly reliable results. The electrochemical parameters associated to impedance study at varying temperatures $(303 \mathrm{~K}, 308 \mathrm{~K}$, $313 \mathrm{~K}$ ) are presented in Table 3 . Results revealed that $\mathrm{I}_{\text {corr }}$ value showed decreasing trend with the increase in concentration of the inhibitor. Nyquist plots of copper in $1 \mathrm{M}$ sulphuric acid solution at 303,308 and $313 \mathrm{~K}$ containing various concentrations of HHDMP after $30 \mathrm{~min}$ of immersion are presented in Fig. 4. The plot of concentration of the inhibitor against efficiency is depicted in Fig. 5. The efficiency is found to be high at $150 \mathrm{ppm}$ of inhibitor HHDMP. It further reveals that in uninhibited solution, Nyquist plot yields a slightly depressed semicircle, and it amply explains that the corrosion of the copper in the absence of inhibitor is mainly controlled by a charge transfer process. [21, 22]. The simplest circuit fit for these experimental data was a Randle's circuit consists of a solution resistance, $R_{\mathrm{s}}$, in series to a parallel combination of resistor, $\mathrm{R}_{\mathrm{ct}}$, and a double-layer capacitor, $\mathrm{C}_{\mathrm{dl}}$. Here $\mathrm{R}_{\mathrm{ct}}$ represents the charge transfer resistance and $\mathrm{C}_{\mathrm{dl}}$ represents the electrode capacitance. It may be noted from Nyquist plots that $R_{c t}$ values increased with inhibitor concentration, which can be attributed to the formation of a protective layer at the metal surface, and this layer acts as a barrier for the mass and the charge transfers. The inhibition efficiency was calculated using the equation

IE $(\%)=\frac{R_{\mathrm{ct}^{*}}-R_{\mathrm{ct}}}{R_{\mathrm{ct}^{*}}} \times 100$,

where $R_{C t^{*}}$ and $R_{C t}$ represent the values of the charge transfer resistance observed in the presence and absence of HHDMP.

\subsection{Adsorption Studies}

The adsorption isotherm provides information pertaining to the interaction of inhibitor with metal surface [23]. Adsorption behaviour of the HHDMP in copper corrosion is presented in Table 3. Results revealed that corrosion behaviour varies with inhibitor concentrations. The surface 


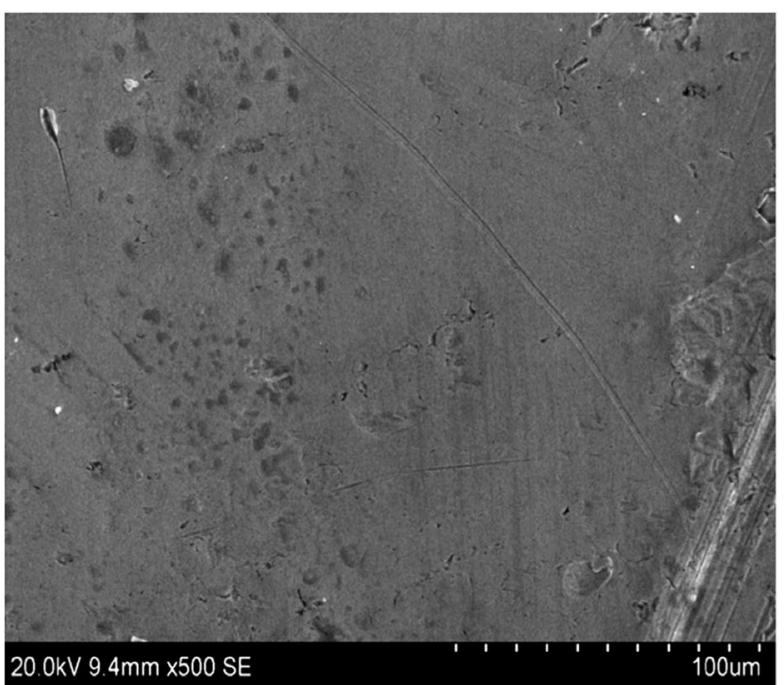

(a)

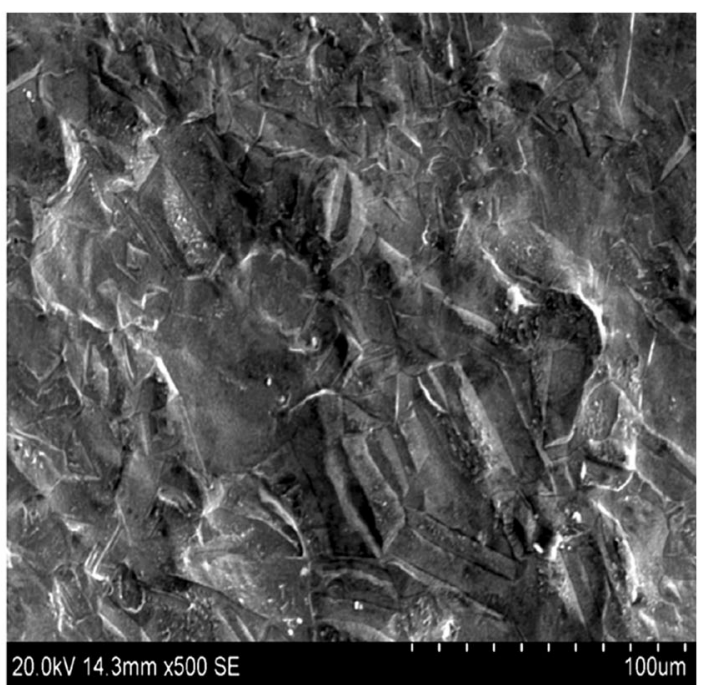

(b)

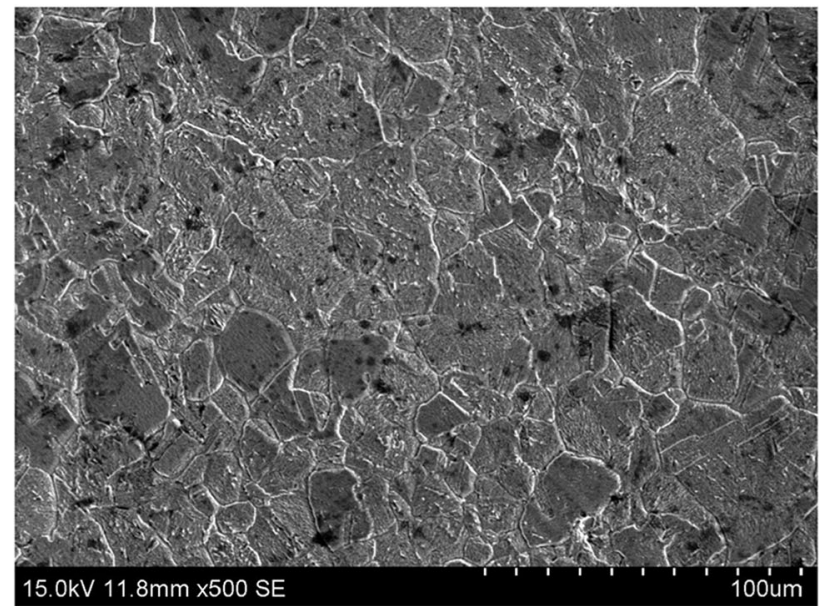

(c)

Fig. 9 The SEM images of a bare polished copper, $\mathbf{b}$ copper after immersion in $1 \mathrm{M}$ sulphuric acid medium without inhibitor and $\mathbf{c}$ copper in the presence of $150 \mathrm{ppm}$ of HHDMP after $24 \mathrm{~h}$ exposure

coverage values $(\theta)$ for different concentrations of inhibitor in $1 \mathrm{M}$ sulphuric acid obtained from electrochemical measurements were used for the construction of adsorption isotherm. Using these data, different isotherms have been plotted to find out the most suitable adsorption isotherm. The plot $\mathrm{C} / \theta$ versus $\mathrm{C}$ shows a straight line, providing that the adsorption of HHDMP on copper surface obeys Langmuir adsorption isotherm, and the same at 303, 308 and $313 \mathrm{~K}$ is shown in Fig. 6. The values of $K_{a d s}$ and $\Delta G_{a d s}^{0}$ of inhibitor HHDMP are presented in Table 4. The negative value of $\Delta \mathrm{G}_{\mathrm{ads}}^{0}$ indicates the spontaneity of adsorption process and stability of the adsorbed layer on the copper surface. Generally, the values of $\Delta \mathrm{G}_{\mathrm{ads}}^{0}$ around $-20 \mathrm{~kJ} \mathrm{~mol}^{-1}$ or lower are consistent with physisorption, while those around $-40 \mathrm{~kJ} \mathrm{~mol}^{-1}$ or higher value involve chemisorptions [24]. In this case, mode of adsorption involved is physisorption.

\subsection{Computational Studies}

Computational calculations of various quantum chemical parameters like energy of highest occupied molecular orbital $\left(E_{\text {НОмо }}\right)$, energy of the lowest unoccupied molecular orbital $\left(E_{L U M O}\right)$, energy gap $(\Delta E)$, i.e., $E_{\text {HOMO }}-E_{\text {LUMO }}$, ionization potential, $I$ which is $-E_{\text {HOMO }}$, electron affinity, $A$ which is $-E_{L U M O}$, electro negativity, $\chi$ which is $(I+A) /$ 2 and hardness, $\eta$ which is $(I-A) / 2$ were calculated, and they optimized the geometry of the molecule using Gaussian 09 program package. The calculated values of quantum chemical parameters are $\mathrm{E}_{\mathrm{HOMO}}(\mathrm{eV})$, ELUMO $(\mathrm{eV})$, $\Delta \mathrm{E}(\mathrm{eV}), \mathrm{I}(\mathrm{eV}), \mathrm{A}(\mathrm{eV}), \chi(\mathrm{eV})$ and $\eta(\mathrm{eV})$ which are found to be $-5.72,-1.62,03,5.72,1.62,3.67$ and 2.05, respectively. The optimized geometry of HHDMP is presented in Fig. 7. HOMO and LUMO of HHDMP are shown in Fig. 8. It is generally stated that the efficiency of 


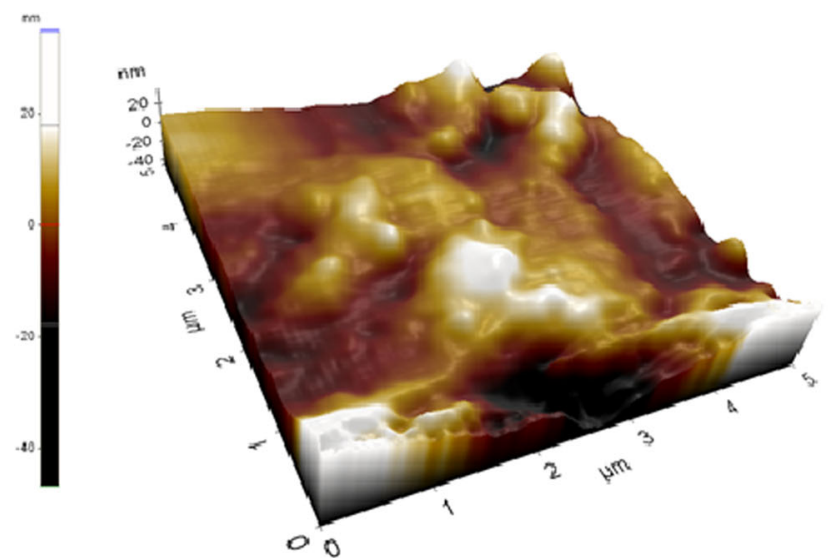

(a)

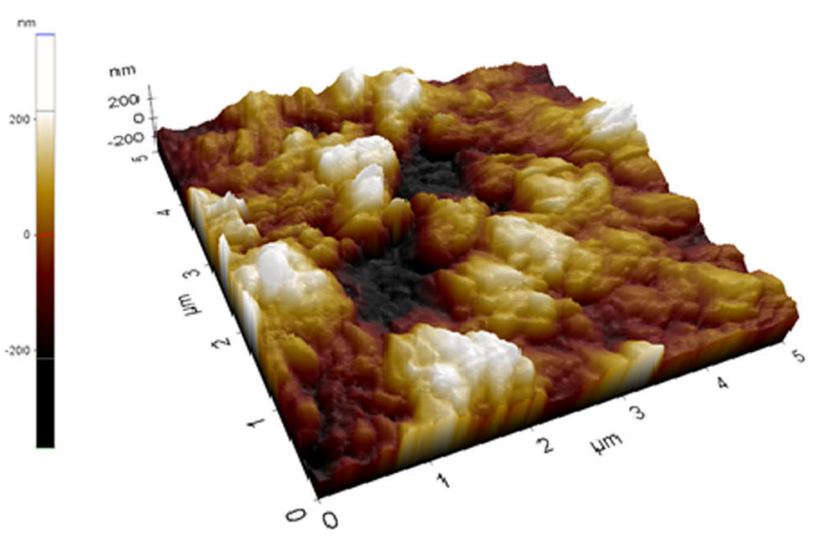

(b)

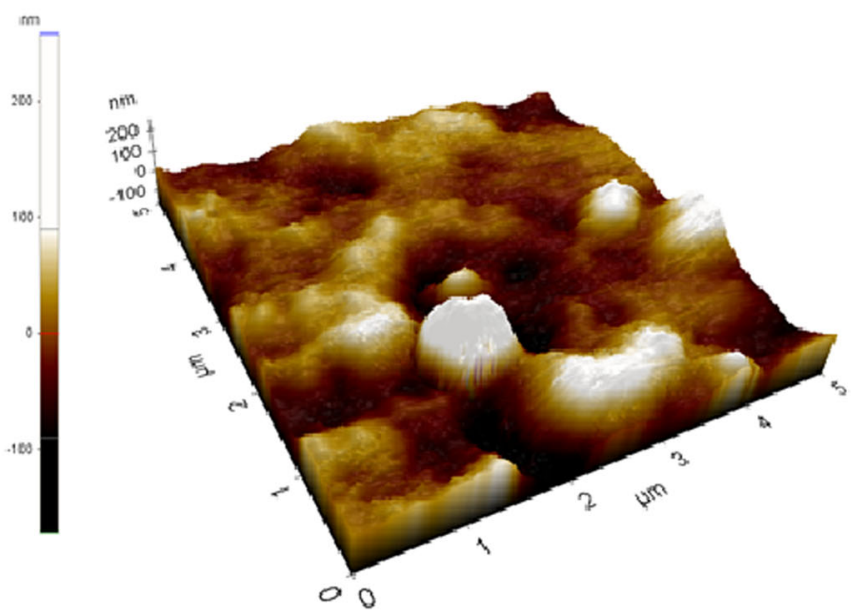

(c)

Fig. 10 AFM images of a copper, b copper in $1 \mathrm{M} \mathrm{H}_{2} \mathrm{SO}_{4}$ without inhibitor and copper in the presence of $150 \mathrm{ppm}$ of $\mathrm{HHDMP}$ after $24-\mathrm{h}$ exposure

inhibitors increases with the decrease in energy gap, $\Delta E$, increase in $E_{\text {НОмO }}$ and decrease in $E_{L U M O}$. Higher $E_{\text {HOMO }}$ value enhances the adsorption of inhibitor, thereby increasing the inhibition efficiency. The smaller the $E_{L U M O}$ value, the greater will be the probability of molecules to accept electrons. The higher the ionization energy, the easier will be the removal of electrons from the molecule.

\subsection{Scanning Electron Microscopy}

SEM studies enable understand the effect of inhibitor molecules on the surface of copper [25-27]. The SEM images of a bare polished copper, copper after immersion in $1 \mathrm{M}$ sulphuric acid without inhibitor and with inhibitor for a period of $24 \mathrm{~h}$ are shown in Fig. 9a-c, respectively. It also revealed that the metal surface was smooth and free from depressions in the case of copper immersed in sulphuric acid containing HHDMP, whereas the surface is damaged in the case of copper immersed in sulphuric acid without inhibitor.

\subsection{Atomic Force Microscope (AFM)}

Atomic force micrographs were taken to study whether inhibition is due to the formation of a film on the metal surface through adsorption $[28,29]$. The three-dimensional AFM images are shown in Fig. 10(a-c). It is evident from Fig. 10c there is much less damage on the surface of copper in the presence of HHDMP. The average roughnesses of polished copper (Fig. 10a) and copper exposed in $1 \mathrm{M} \mathrm{H}_{2} \mathrm{SO}_{4}$ without inhibitor (Fig. 10b) were calculated to be 6.84 and $84 \mathrm{~nm}$, respectively. The copper surface exposed in free acid solution is getting cracked considerably due to the attack of ionic species (Fig. 10b), and the 
same can be moderately controlled by the usage of $150 \mathrm{ppm}$ of inhibitor where the average roughness was reduced to $33.72 \mathrm{~nm}$.

\section{Conclusions}

(1) The amino acid Schiff base HHDMP is a green corrosion inhibitor with fairly good efficiency.

(2) As the concentration of the inhibitor increases, corrosion inhibition efficiency as well as charge transfer resistance increases.

(3) The corrosion rate and double-layer capacitance decreased due to increased adsorption of the inhibitor.

(4) The inhibitor molecule affects both the anodic and cathodic processes and hence acts as a mixed type inhibitor.

(5) The adsorption of the inhibitor obeys Langmuir adsorption isotherm model.

(6) HHDMP inhibits copper corrosion in $1 \mathrm{M} \mathrm{H}_{2} \mathrm{SO}_{4}$ even at fairly high temperature also.

\section{References}

1. Finsgar M, Milosev I (2010) Inhibition of copper corrosion by 1,2, benzotriazole: a review. Corros Sci 52:2737-2749

2. Drach A, Tsukrov I, DeCew J, Aufrecht J, Grohbauer A, Hofmann U (2013) Field studies of corrosion behaviour of copper alloys in natural seawater. Corros Sci 76:453-464

3. Li W, Hu L, Zhang S, Hou B (2011) Effects of two fungicides on the corrosion resistance of copper in $3.5 \% \mathrm{NaCl}$ solution under various conditions. Corros Sci 53:735-745

4. Tian H, Li W, Cao K, Hou B (2013) Potent inhibition of copper corrosion in neutral chloride media by novel non-toxic thiadiazole derivatives. Corros Sci 73:281-291

5. Sudheer Quraishi M A (2013) Electrochemical and theoretical investigation of triazole derivatives on corrosion inhibition behaviour of copper in hydrochloric acid medium. Corros Sci 70:161-169

6. Curkovic HO, Stupnisek-Lisac E, Takenouti H (2010) The influence of $\mathrm{pH}$ value on the efficiency of imidazole based corrosion inhibitors of copper. Corros Sci 52:398-405

7. Zhang DQ, Cai QR, He XM, Gao LX, Kim GS (2009) The corrosion inhibition of copper in hydrochloric acid solutions by a tripeptide compound. Corros Sci 51:2349-2354

8. Khaled KF, Mohammed A (2009) Dry and wet lab studies for some benzotriazole derivatives as possible corrosion inhibitors for copper in 1.0 M HNO3. Corros Sci 51:2098-2106

9. Tansug G, Tukenb T, Giray ES, Findıkkıranb G, Sigrcık G, Demirkol O, Erbil M (2014) A new corrosion inhibitor for copper protection. Corros Sci 84:21-29

10. Pan YC, Wen Y, Guo XY, Song P, Shen S, Du YP, Yang HF (2013) 2-Amino-5-(4- pyridinyl)-1,3,4-thiadiazole monolayers on copper surface: observation of the relationship between its corrosion inhibition and adsorption structure. Corros Sci 73:274-280
11. Hong S, Chen W, Zhang Y, Luo HQ, Li M, Li NB (2013) Investigation of the inhibition effect of trithiocyanuric acid on corrosion of copper in $3.0 \mathrm{wt} \% \mathrm{NaCl}$. Corros Sci 66:308-314

12. Behpour M, Mohammadi N (2012) Investigation of inhibition properties of aromatic thiol self-assembled monolayer for corrosion protection. Corros Sci 65:331-339

13. Chen W, Hong S, Li HB, Luo HQ, Li M, Li NB (2012) Protection of copper corrosion in $0.5 \mathrm{M} \mathrm{NaCl}$ solution by modification of 5-mercapto-3-phenyl-1, 3, 4-thiadiazole-2-thione potassium selfassembled monolayer. Corros Sci 61:53-62

14. Sakiyan I, Gunduz N, Gunduz T (2001) Synthesis and characterization of Manganese (III) complexes of schiff base derived from amino acids and 2-hydroxy 1-Naphthaldehyde. Synth React Inorg Met Org Chem 31:1175-1187

15. Bentiss F, Traisnel M, Lagrenee M (2001) Influence of 2, 5-bis (4- dimethyl amino phenyl) - 1, 3, 4- thiadiazole on corrosion inhibition of mild steel in acidic media. J Appl Electrochem 31:41-48

16. Finsgar M, Kek Merl D (2013) 2-Mercaptobenzoxazole as a copper corrosion inhibitor in chloride solution: electrochemistry, 3D-profilometry, and XPS surface analysis. Corros Sci 80:82-95

17. Finsgar M (2013) 2-Mercaptobenzimidazole as a copper corrosion inhibitor: part I. Long-term immersion, 3D-profilometry, and electrochemistry. Corros Sci 72:82-89

18. Lee Yang W, Parr RG (1988) Development of the colle-salvetti correlation energy formula of the electron density. Phys Rev B 37:785-789

19. Ignaczak A, Gomes JNF (1996) Interaction of halide ions with copper: the DFT approach. Chem Phys Lett 257:609-615

20. Lashkari M, Arshadi MR (2004) DFT studies of pyridine corrosion inhibitors in electrical double layer: solvent, substrate, and electric field effects. Chem Phys 299:131-137

21. Kuruvilla Mathew, John Sam, Joseph Abraham (2013) Res Chem Intermed 39:3531

22. Champion FA (1964) Corrosion testing procedure, 2nd edn. Chapman and Hall, London, p 32

23. Solmaz R, Kardas G, Culha M, Yazici B, Erbil M (2008) Investigation of adsorption and inhibitive effect of 2-mercaptothiazoline on corrosion of mild steel in hydrochloric acid media. Electrochim Acta 53:5941-5952

24. El Achouri M, Kertit S, Gouttaya HM, Nciri B, Bensouda Y, Perez L, Infante MR, Elkacemi K (2001) Corrosion inhibition of iron in $1 \mathrm{M} \mathrm{HCl}$ by some gemini surfactants in the series of alkanediyl- $\alpha$, $\omega$-bis-(dimethyl tetradecyl ammonium bromide). Prog Org Coat 43:267-273

25. Kaan EC, Akay AA, Atakol O (2005) The corrosion inhibition of steel with Schiff base compounds in $2 \mathrm{M} \mathrm{HCl}$. Mat Chem Phy 93:325-329

26. Azim A, Shalaby LA, Abbas H (1974) Mechanism of the corrosion inhibition of $\mathrm{Zn}$ Anode in $\mathrm{NaOH}$ by gelatine and some inorganic anions. Corros Sci 14:21-24

27. Lebrini M, Lagrenee M, Vezin H, Gengembre L, Bentiss F (2005) Electrochemical and quantum chemical studies of new thiadiazole derivatives adsorption on mild steel in normal hydrochloric acid medium. Corros Sci 47:485-505

28. Musa AY, Kadhum AAH, Mohamed AB, Takriff MS (2010) Experimental and theoretical study on the inhibition performance of triazole compounds for mild steel corrosion. Corros Sci 52:3331-3340

29. Touhami F, Aouniti A, Abed Y, Hammouti B, Kertit S, Ramdani A, Elkacemi K (2000) Corrosion inhibition of armco iron in $1 \mathrm{M}$ $\mathrm{HCl}$ media by new bipyrazolic derivatives. Corros Sci 42:929-940 